NASA Technical Memorandum 4798

\title{
Emergency Flight Control Using Only Engine Thrust and Lateral Center-of-Gravity Offset: A First Look
}

Frank W. Burcham, Jr., John Burken, and Trindel A. Maine, Dryden Flight Research Center Edwards, California

John Bull

CAELUM Research Corporation NASA Ames Research Center Moffett Field, California

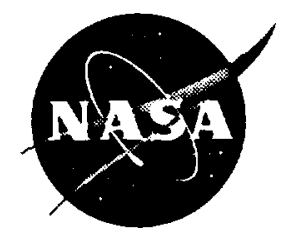

National Aeronautics and Space Administration Office of Management Scientific and Technical Information Program 



\title{
EMERGENCY FLIGHT CONTROL USING ONLY ENGINE THRUST AND LATERAL CENTER-OF-GRAVITY OFFSET: A FIRST LOOK
}

\author{
Frank W. Burcham, Jr., ${ }^{*}$ John Burken, ${ }^{\dagger}$ Trindel A. Maine ${ }^{\ddagger}$ \\ NASA Dryden Flight Research Center \\ Edwards, California \\ John Bull ${ }^{\ddagger}$ \\ CAELUM Research Corporation \\ NASA Ames Research Center \\ Moffett Field, California
}

\begin{abstract}
Normally, the damage that results in a total loss of the primary flight controls of a jet transport airplane, including all engines on one side, would be catastrophic. In response, NASA Dryden has conceived an emergency flight control system that uses only the thrust of a wingmounted engine along with a lateral center-of-gravity (CGY) offset from fuel transfer. Initial analysis and simulation studies indicate that such a system works, and recent high-fidelity simulation tests on the MD-11 and B-747 suggest that the system provides enough control for a survivable landing. This paper discusses principles of flight control using only a wing engine thrust and CGY offset, along with the amount of CGY offset capability of some transport airplanes. The paper also presents simulation results of the throttle-only control capability and closed-loop control of ground track using computer-controlled thrust.
\end{abstract}

\section{Nomenclature}

AGL above ground level (radar altitude)

CGX longitudinal center of gravity, percent of mean aerodynamic chord

CGY lateral center of gravity, distance from fuselage centerline, in.

EPR engine pressure ratio

FADEC full authority digital engine control

FDS flight deck simulator

\footnotetext{
*Chief, Propulsion Branch. Associate Fellow ALAA

${ }^{\dagger}$ Aerospace Engineer.

$\ddagger$ Aerospace Engineer. Member AIAA.

Copyright (C) 1997 by the American Institute of Aeronautics and Astronautics, Inc. No copyright is asserted in the United States under Title 17, U.S. Code. The U.S. Government has a royalty-free license to exercise all rights under the copyright claimed herein for Governmental purposes. All other rights are reserved by the copyright owner.
}

FPA flightpath angle, deg

GW gross weight, lb

HDG heading (magnetic direction that the airplane is pointed toward)

PCA propulsion-controlled aircraft

$t \quad$ time, sec

TRK track angle (magnetic direction of ground track)

\section{Introduction}

Many occurrences have required the use of engine thrust to supplement or replace an aircraft's normal flight controls. In most of these cases, crashes have resulted, with more than 1200 lives lost. ${ }^{1}$ NASA Dryden Flight Research Center has developed a propulsion-controlled aircraft (PCA) system in which computer-controlled thrust provides emergency flight control capability without using any of the normal flight control surfaces. Using this PCA system, an F-15 and an MD-11 airplane have landed without using any flight controls. ${ }^{1,2}$ In simulations, PCA systems were developed and successfully tested on a B-720, a generic twin jet and a B-747 at NASA Ames, a conceptual megatransport, and a C-17 military transport. ${ }^{3-6}$ In all cases, the thrust of engines on both sides of the airplane was available.

Consider an airplane with only the engine or engines on one wing still operating: Could emergency flight control be provided? In response to this question, NASA Dryden has taken a first look at a concept showing that one engine can provide limited flight control capability if the lateral center of gravity (CGY) is shifted toward the wing with the operating engine. Limited simulation tests with all conventional flight controls inoperative and a wing engine inoperative on the MD-11 show positive flight control capability within the available range of CGY offset. On four-engine airplanes, simulations of the B-720 at NASA Dryden and the B-747 at NASA Ames

1 
also show positive control capability within the available range of CGY offset.

This paper presents the concept of flying an airplane with no conventional flight control surfaces, using the engine thrust on only one wing and a CGY offset. The paper also presents the principles of operation and shows preliminary simulation results from MD-11 and B-747 airplanes.

Use of trade names or names of manufacturers in this document does not constitute an official endorsement of such products or manufacturers, either expressed or implied, by the National Aeronautics and Space Administration.

\section{Flight Control Using Only Engine Thrust}

If an airplane's normal flight control surfaces fail for some reason, engine thrust can be used to provide gross control of flightpath and bank angle. In the following subsections, manual throttle manipulation by the pilot is discussed first; then a closed-loop PCA system is described.

\section{Manual Throttles-Only Control}

With flight control surfaces inactive, a flight crew can use the throttles for flight control. Differential throttle inputs cause yaw, which through the dihedral effect causes roll. With proper differential thrust control, bank angle can be modulated and used to control heading to within a few degrees. Collective thrust provides pitch control: Thrust increase will increase the flightpath angle and thrust decrease will decrease the flightpath angle. With proper collective throttle control, pitch can be controlled to within a few degrees. Unfortunately, manual throttle control is not adequate for achieving a safe landing. Difficulties arise from the small moments, the slow response, and the difficulty in damping the phugoid and dutch-roll oscillations. Burcham et al. discussed the principles of thrust-only flight control. ${ }^{1}$

\section{PCA System and Prior Results}

The PCA system, using computer-controlled thrust, has been shown to provide emergency flight control capability suitable for safe landings. In the PCA system, pilot commands are compared with the measured feedback parameters, and thrust commands are computed and sent to the engines. Simulations of PCA systems on the F-15, C-17, MD-11, B-720, B-747, and a conceptual megatransport all have shown the ability to make safe landings. Flight tests of PCA systems have been conducted on the F-15 and MD-11, with safe landings made on both airplanes without movement of the flight control surfaces.

Figure 1 is a schematic diagram of the MD-11 PCA system. Existing autopilot controllers in the cockpit are used for pilot inputs. Control laws reside in the existing

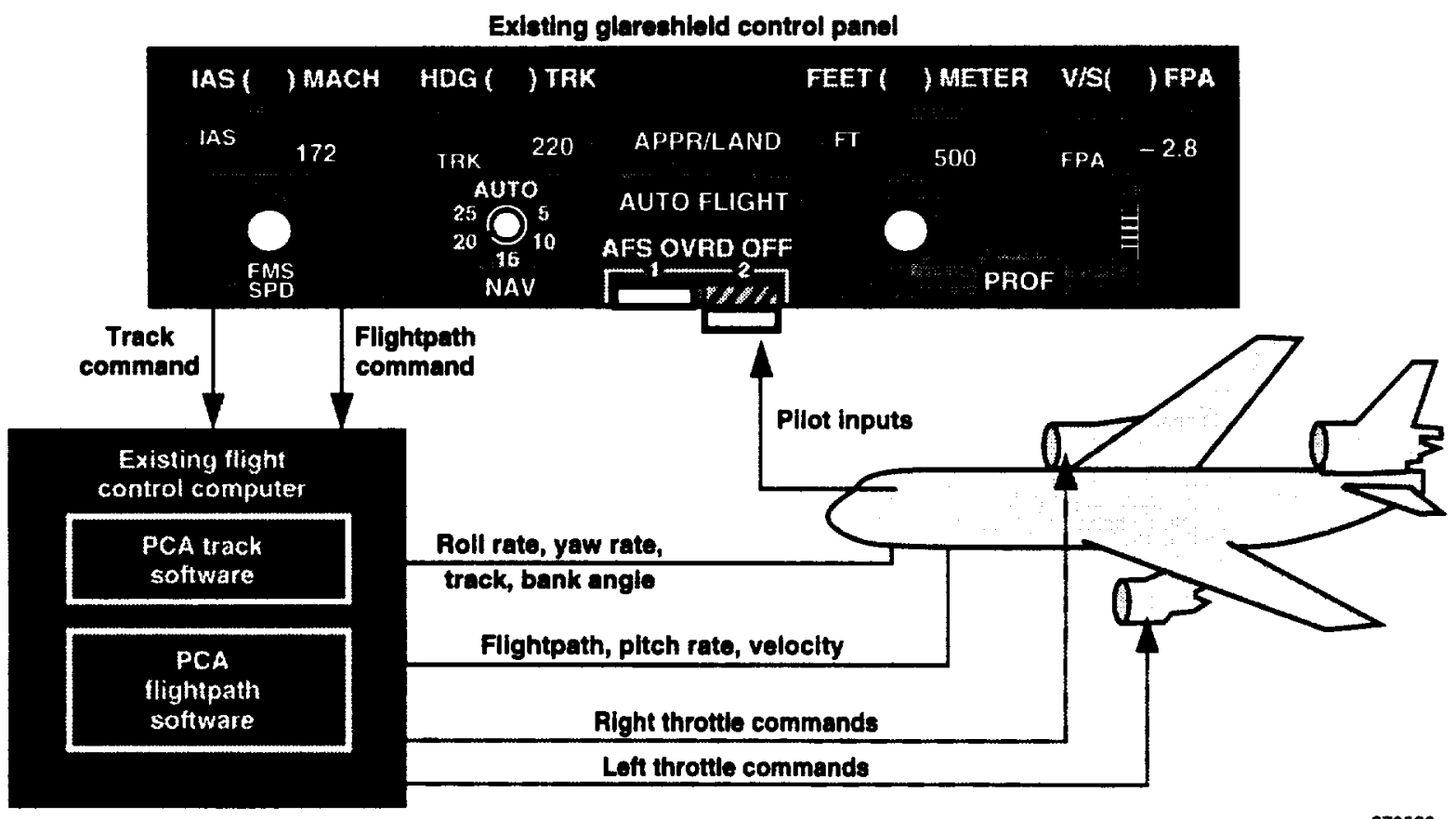

Figure 1. The MD-11 PCA system. 
flight control computer. Pilot track command is compared with the measured track. Feedback parameters, such as yaw rate and roll rate, provide dutchroll damping, and differential throttle commands are computed. In the pitch axis, pilot flightpath angle (FPA) thumbwheel commands are compared with the measured FPA, with pitch rate and velocity feedback provided for phugoid damping, and collective thrust commands are computed. The track and flightpath commands are combined and thrust commands are issued over the existing data bus to the engine full authority digital engine control (FADEC) systems. Only software changes were required to implement the MD-11 PCA system. Burcham et al. provided more details of the MD-11 PCA system. ${ }^{2}$

The B-747 and C-17 PCA systems were similar to the MD-11 in concept, also using existing cockpit autopilot controls for pilot commands. In all of the PCA systems, track is typically controlled to within a degree of command, and FPA is typically controlled to within $\pm 0.5^{\circ}$ of command. In all of these studies, engines were operational on both sides of the airplanes.

\section{Principles of Control With CGY Offset}

Consider now an airplane with inoperative flight control surfaces and all engines inoperative on one wing (fig. 2). If the CGY can be offset toward the side with the operating engine(s), the engine's thrust creates a yawing moment and a resulting rolling moment (from the dihedral effect) counter to that rolling moment resulting from weight times the offset distance CGY. Depending on the available thrust and degree of CGY offset, a certain thrust level creates a rolling moment that exactly counters the rolling moment due to the CGY offset, resulting in zero roll rate.

Increasing the thrust above this level results in the airplane rolling away from the operating engine, while decreasing the thrust below this level results in rolling toward it. Modulating thrust thus allows bank angle control and wings-level flight. Because the laterally offset thrust generates rolling moment indirectly through forces applied in the yaw axis, a steady-state sideslip occurs; thus a corresponding steady-state bank angle is required to maintain a constant heading.

The overall thrust level also determines the FPA of the airplane for a given aircraft configuration. Thus, a strong coupling exists between the longitudinal and lateraldirectional axis. In particular, the thrust level needed to provide a desired FPA is unlikely to be the thrust level needed to maintain a desired bank angle. Larger CGY offsets require larger thrust levels to counteract and result in a more positive FPA; therefore, control of the degree of CGY offset provides FPA control.

Figure 3 shows a diagram of this control scheme. The feedback and throttle commands can be performed

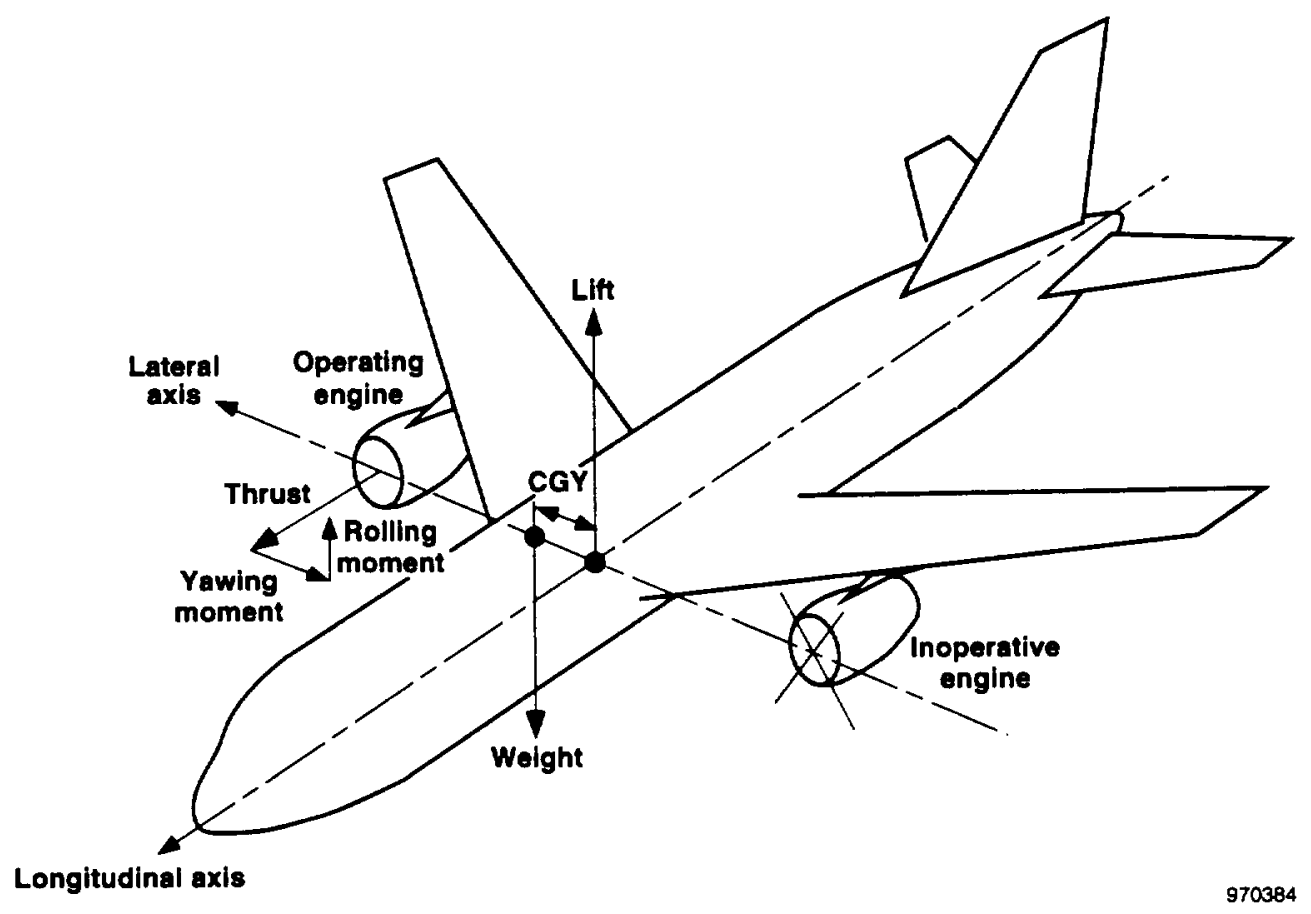

Figure 2. Forces and moments on an airplane with a wing engine inoperative and a CGY offset. 


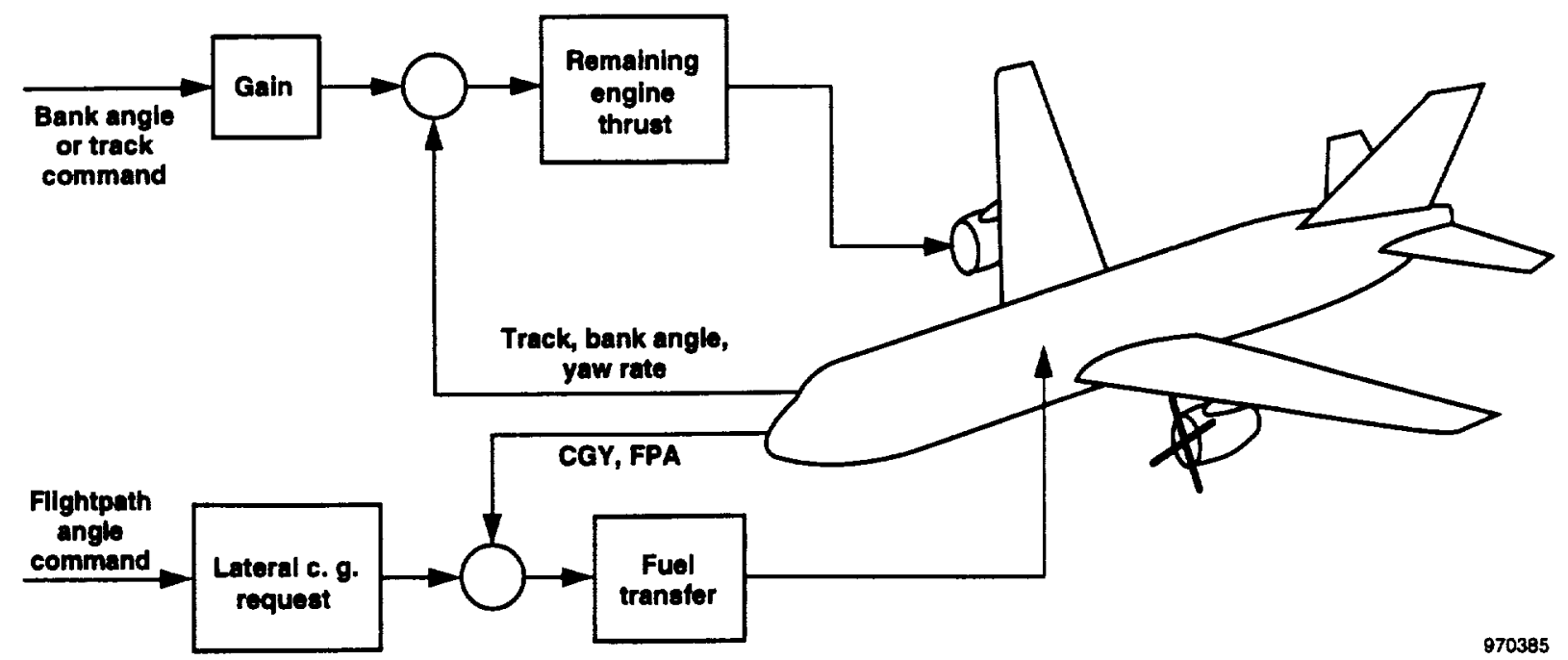

Figure 3. Longitudinal and lateral flight control scheme for an airplane with inoperative flight control surfaces, one wing engine inoperative, and a CGY offset.

manually by the pilot or electronically by an automatic system. While damping of the dutch-roll mode can generally be accomplished with an electronic system with the use of proper feedback parameters, a pilot will find this a daunting task. The simultaneous damping of phugoid motions in the pitch axis and dutch roll in the lateral axis has not been demonstrated in this first look but will likely be extremely difficult, if not impossible, with a single-wing engine.

On a four-engine airplane with two engines inoperative on the same wing, additional capability exists for providing limited flightpath control as well as bank angle control by varying the thrust split between the remaining inboard engine and outboard engine. Figure 4 shows a diagram of the control scheme for the four-engine airplane. Again, the pilot can provide the feedbacks or an electronic system can do this automatically. With two engines available, better potential exists for simultaneous phugoid damping and dutch-roll damping, but this has not yet been attempted.

On three-engine airplanes with an operating engine on the centerline and another on one wing, the center engine may be used for pitch control with the wing engine used for lateral control. Here, the pitch-roll interactions can be less severe and better control can be achieved, depending on the exact configuration.

\section{Airplanes Tested in Simulations}

Preliminary studies of the MD-11 and B-747 airplanes in high-fidelity simulations have been performed. The following four subsections briefly describe the airplanes and the simulations.

\section{MD-11 Airplane}

The MD-11, built by McDonnell Douglas Corporation (Long Beach, California), is a large long-range widebody transport powered by three engines. Each engine is in the 60,000 -1b thrust class: two are on underwing pylons and one is mounted in the base of the vertical tail (fig. 5). The wing engines are $26 \mathrm{ft}, 10 \mathrm{in}$. from the centerline. Each wing fuel tank holds $42,000 \mathrm{lb}$ of fuel, a tank in the horizontal tail holds $13,100 \mathrm{lb}$, and the center fuselage tanks holds $162,000 \mathrm{lb}$. Maximum takeoff gross weight is $630,000 \mathrm{lb}$, and maximum landing weight is $430,000 \mathrm{lb}$.

\section{MD-11 Simulation}

The MD-11 Flight Deck Simulator (FDS) is a highfidelity, fixed-base simulation of the MD-11 that contains much actual flight hardware. The FDS incorporates six degree-of-freedom equations of motion, complete aerodynamic and propulsion models, analytical models of all of the MD-11 systems, and a projected video outthe-window display system. The simulated MD-11 is powered by Pratt \& Whitney (East Hartford, Connecticut) PW4460 engines with $60,000 \mathrm{lb}$ thrust each. Thrust as a function of engine pressure ratio (EPR) for the PW4460 engine is a nonlinear function, with about $97,000 \mathrm{lb} / \mathrm{EPR}$ at low thrust and about $57,000 \mathrm{lb} / E P R$ near maximum thrust. 


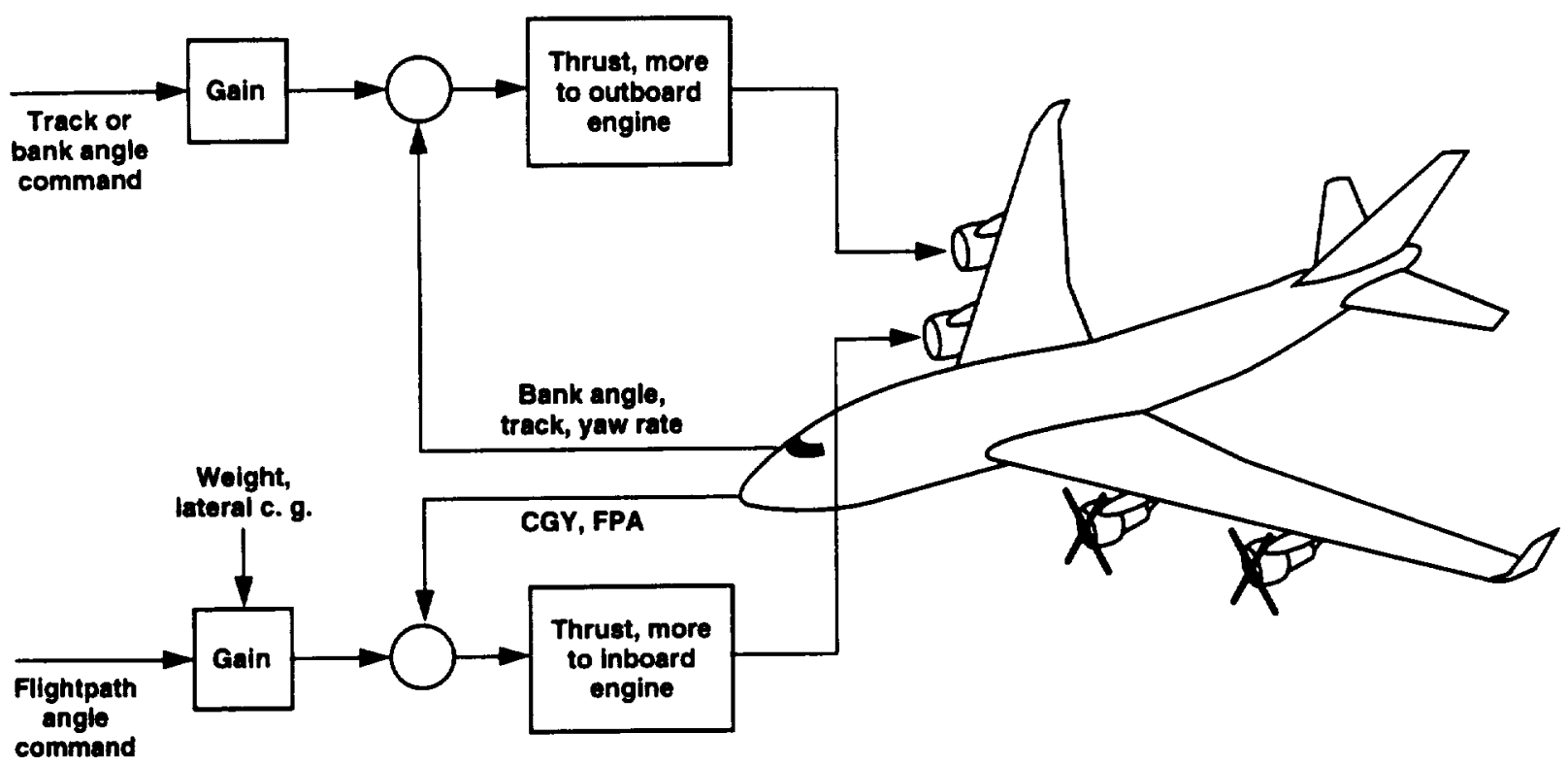

970386

Figure 4. Longitudinal and lateral control of an emergency flight control scheme with two engines inoperative on one side and a CGY offset.

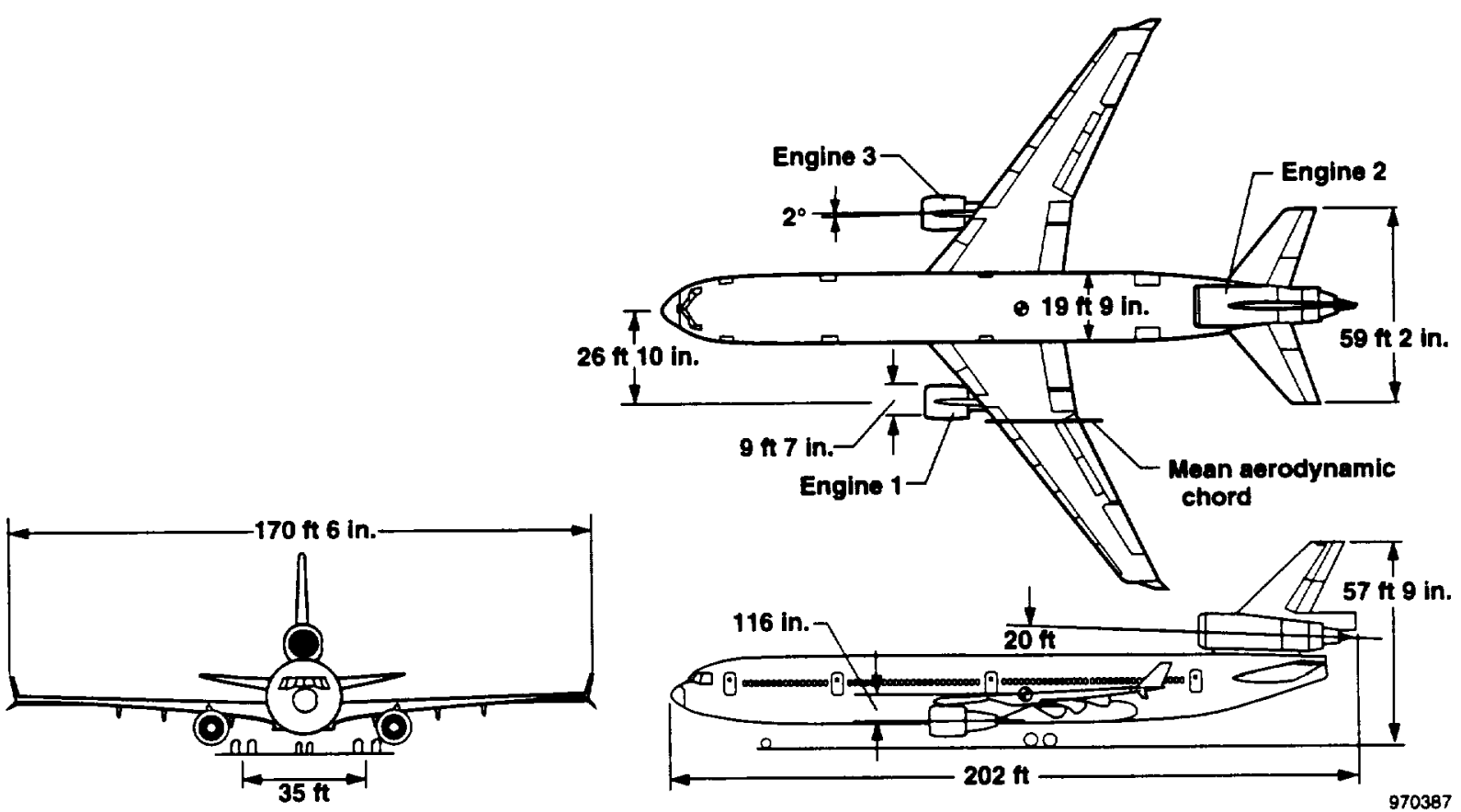

Figure 5. Three-view of the MD-11 airplane.

\section{B-747 Aimplane}

The B-747, drawn in figure 6 , is a very large sweptwing wide body transport with four engines mounted on underwing pylons, and is built by The Boeing Company
(Seattle, Washington). Maximum gross weight is up to $870,000 \mathrm{lb}$; maximum landing weight is $574,000 \mathrm{lb}$. The inboard engines are $39 \mathrm{ft}$ from the centerline, while the outboard engines are $70 \mathrm{ft}$ from the centerline. Wing fuel capacity is $84,000 \mathrm{lb}$ in each inboard tank and $30,000 \mathrm{lb}$ 


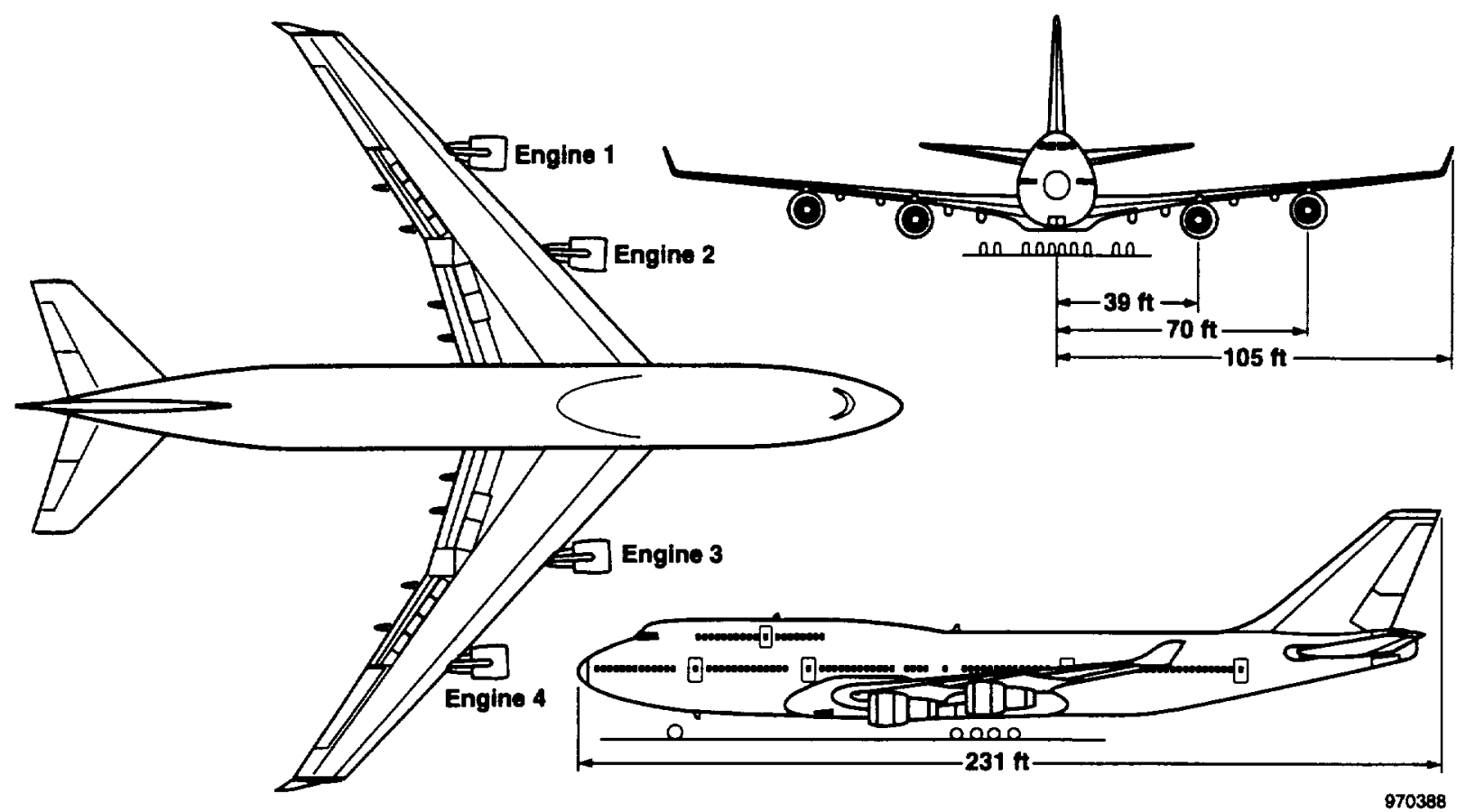

Figure 6. Three-view of the B-747 airplane.

in each outboard tank. Additional fuel tanks are in the center fuselage and horizontal tail, for a maximum fuel weight of $386,000 \mathrm{lb}$.

\section{B-747 Simulation}

Tests have been performed on the B-747-400 simulator at NASA Ames. This very high fidelity, motion-base simulator is certified to level D. The 747-400 simulated is powered by Pratt \& Whitney PW4056 engines with $56,000 \mathrm{lb}$ of thrust. Thrust as a function of EPR for the PW4056 engine is a nonlinear function, with about $90,000 \mathrm{lb} / \mathrm{EPR}$ at low thrust and about $45,000 \mathrm{lb} / \mathrm{EPR}$ near maximum thrust.

\section{Capability to Shift CGY}

The fuel systems of some airplanes have been studied to determine the degree of CGY that can be obtained. The MD-11 is typical of many transport airplanes, having most of the fuel in the wings and center fuselage. Each wing tank holds $42,000 \mathrm{lb}$ of fuel. The remaining fuel is in the center fuselage tanks and in a small tail tank used to provide longitudinal center-of-gravity (CGX) control. Fuel distribution is normally controlled by the fuel management system, which maintains a programmed CGX schedule; but fuel may also be manually transferred among tanks. After takeoff, fuel is normally transferred to the tail tank to move the CGX aft. In an emergency, all but $40,000 \mathrm{lb}$ of fuel can be dumped overboard. A manual fuel switch can disable automatic fuel transfer and CGX control.

Figure 7 shows the offset in CGY as a function of fuel quantity. If one wing tank is full and the other is empty, there is a CGY offset of $48 \mathrm{in}$. With all tanks full, obviously no offset is possible. As fuel is burned or dumped, the maximum offset occurs after the tanks in one wing are empty, and can be maintained as long as there is fuel in the center or tail tanks to keep the other wing tank full. After the center and tail tanks are empty, the CGY offset decreases until, with all fuel exhausted, it is again zero.

A similar situation occurs on other airplanes studied. The four-engine transport airplanes studied include the B-747, Convair 990, and C-17. Table 1 shows the maximum CGY offsets available and the CGY normalized by wingspan for these four airplanes. All show a similar capability of between 2.4 and 3.5 percent of total wingspan.

These CGY offsets are also well within the tread of the main landing gear, so there would be no tipover tendency. 


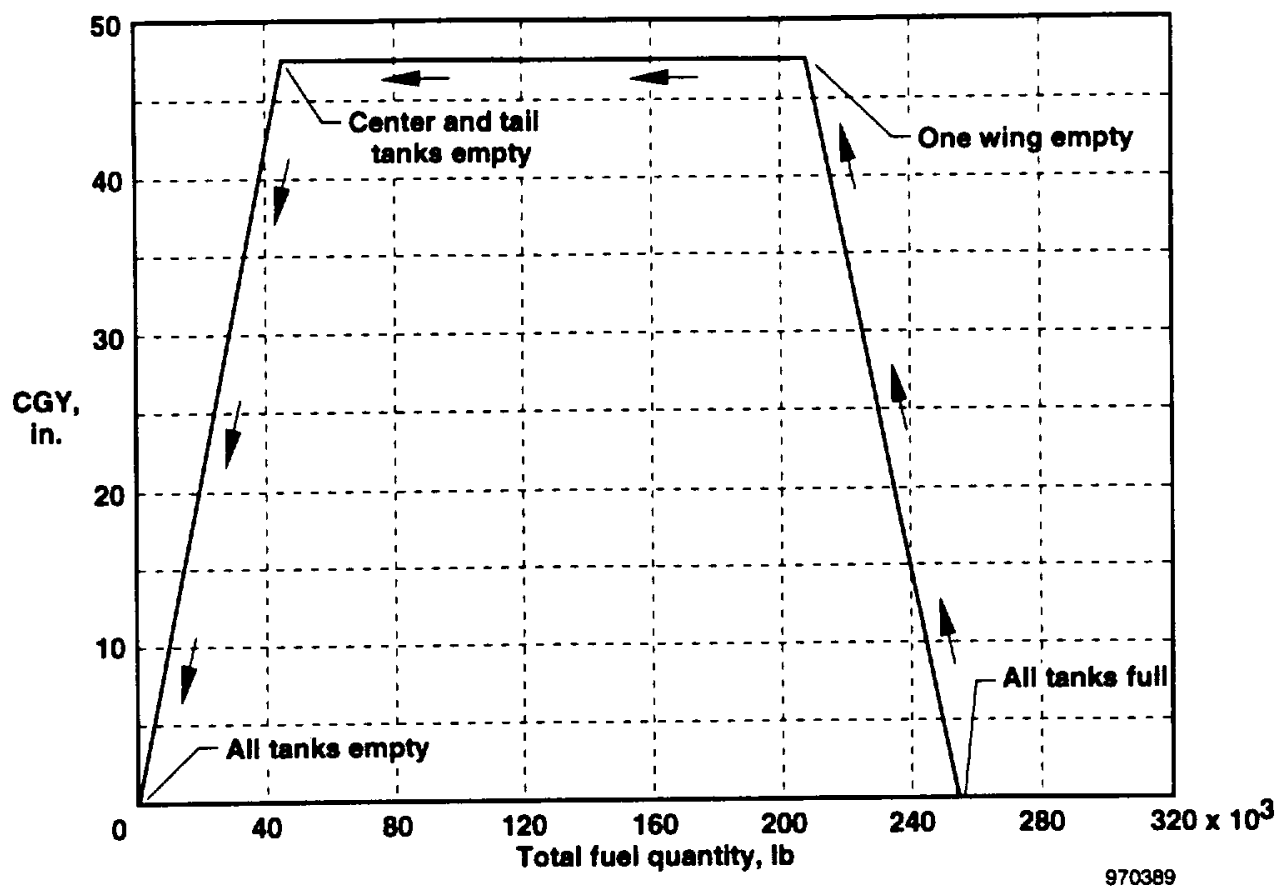

Figure 7. CGY for the MD-11 as a function of total fuel quantity.

Table 1. Maximum CGY offset for four transport airplanes.

\begin{tabular}{ccccc}
\hline \hline Airplane & $\begin{array}{c}\text { Maximum } \\
\text { differential } \\
\text { fuel, lb }\end{array}$ & $\begin{array}{c}\text { CGY, } \\
\text { in. }\end{array}$ & $\begin{array}{c}\text { Overall } \\
\text { wingspan, } \\
\mathrm{ft}\end{array}$ & $\begin{array}{c}\text { CGYI } \\
\text { span }\end{array}$ \\
\hline MD-11 & 42,000 & 48 & 170 & 0.024 \\
B-747 & 114,000 & 70 & 211 & 0.028 \\
C-17 & 90,000 & 66 & 165 & 0.033 \\
CV-990 & 40,300 & 51 & 120 & 0.035 \\
\hline \hline
\end{tabular}

\section{Thrust-Only Control Capability With CGY Shifted}

The thrust-only control capability of the MD-11 and B-747 has been studied in high-fidelity simulators, described previously. Results are given below.

\section{Results of MD-11 Simulation}

On the MD-11, a CGY offset of up to 48 in. can be obtained using the existing fuel system. Figure 8 shows MD-11 FDS results of the time required for the fuel transfer, based on the normal fuel pump operational rates. Starting with all wing tanks equally full, it takes about 7 min to get CGY to a value of 25 in., transferring from the left to the right wing. At this time the right wing is full, and further transfer is from the left wing to the center tank, which is obviously less effective in shifting CGY. After $13 \mathrm{~min}, \mathrm{CGY}$ is $40 \mathrm{in}$., and the maximum tested CGY of 45 in. was reached in $15 \mathrm{~min}$. An average rate of change of $\mathrm{CGY}$ is $\approx 3 \mathrm{in} / \mathrm{min}$.

Tests were performed in the FDS by turning off the yaw dampers and longitudinal stability augmentation systems and not touching the flight controls, thereby eliminating any control surface movement. Beginning from a trimmed condition, both wing engine throttles were retarded to idle and fuel transfer was begun. As CGY increased, the thrust required for wings-level flight gradually increased. Figure 9 shows the engine 3 EPR required to hold wings level (with engine 1 either at idle or off) as a function of speed at an altitude of $10,000 \mathrm{ft}$ with gear and flaps up. Well within the available CGY offset, wings-level flight on one engine was possible over a range of speeds from 200 to $300 \mathrm{kn}$, as shown. As speed increased, the CGY required for wings-level flight decreased because, as airspeed increased, the yawing moment from thrust produced less sideslip and hence, less roll. At $300 \mathrm{kn}$, almost full thrust on engine 3 was required to hold the wings level, and if CGY was increased beyond approximately 30 in., there was not enough thrust to prevent a roll to the right. 


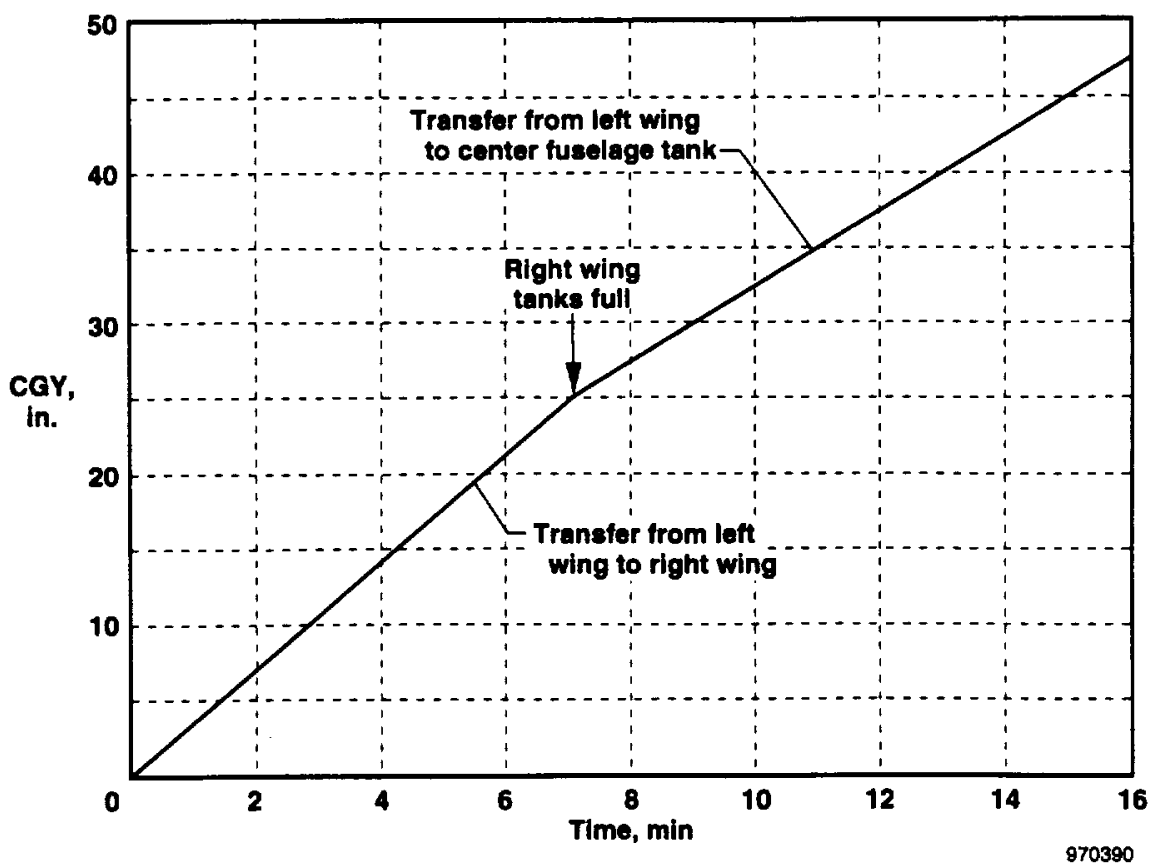

Figure 8. Time history of fuel transfer and CGY for the FDS of the MD-11. (Initial wing fuel tank quantities of approximately $31,000 \mathrm{lb}$.)



Figure 9. Effect of CGY on EPR of engine 3 required for wings-level flight; flaps and slats up; gear up; altitude $\approx 10,000 \mathrm{ft} ; \mathrm{GW} \approx 400,000 \mathrm{lb}$; engine 2 idle.

Also shown in figure 9 is a shaded band that represents a thrust value that will result in an FPA of zero degrees. Conditions above the band will result in a climb, while conditions below the band will result in a descent. Note that this band is for the MD-11 with the center engine at idle, and thus approximates a twin-jet airplane. In the MD-11, the center engine thrust could be used to provide an essentially independent means of FPA control. 
Figure 10 shows a time history of an open-loop throttle step increase followed by a step decrease to idle at $205 \mathrm{kn}$ with gear and flaps up, the left and center engines at idle, and CGY $=35$ in. The initial EPR is 1.18 with a sideslip of $2^{\circ}$. When the thrust increase occurred, sideslip increased and the roll rate generated was $-5 \% \mathrm{sec}$. Angle of attack also increased because the engine was below the CGX as well as to the right of the CGY. As the bank angle passed through $40^{\circ}$, the right engine thrust was reduced to idle, which caused the sideslip to go to zero and the roll rate to reverse to approximately $4 \%$ sec.
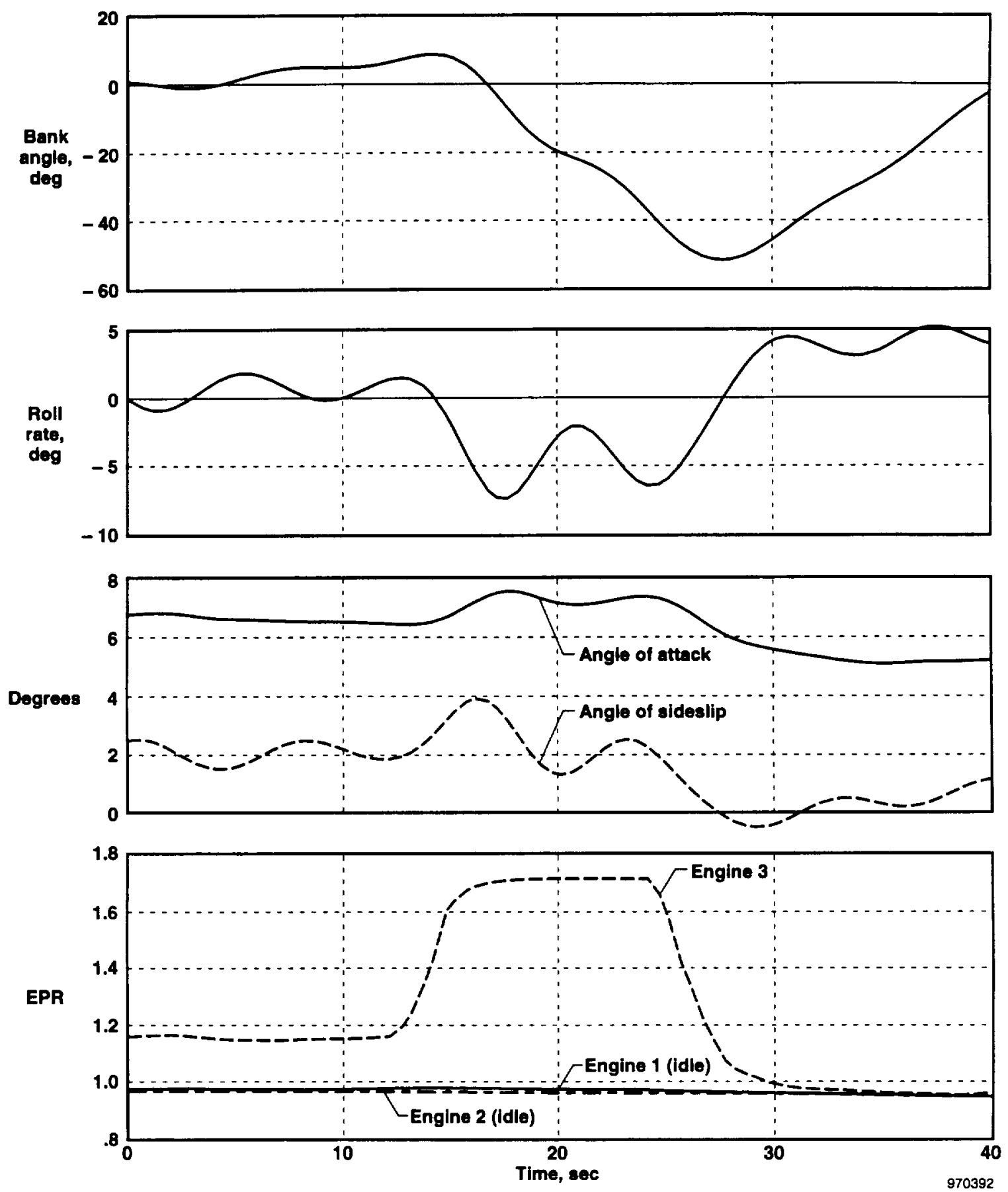

Figure 10. Time history of response to engine 3 throttle step inputs on MD-11 FDS; $205 \mathrm{kn}$; altitude $=7500 \mathrm{ft}$; gear and flaps up; dampers off; $\mathrm{CGY}=35 \mathrm{in}$. 
In other tests at $300 \mathrm{kn}$, the sideslip required for wings-level flight was only $1^{\circ}$, but this took nearly full thrust. Maximum roll rates up to $4^{\circ}$ to $5 \% \mathrm{sec}$ are possible; although depending on speed, they may not be equal in each direction. These rates should be adequate for runway lineup in turbulence up to and including light.

Manual throttles-only control in this configuration, using the scheme of figure 3 , was, as expected, extremely difficult, but with some practice gross control could be maintained and was used to obtain the data shown in figure 10 . Control was greatly improved with the use of a closed-loop automatic control system. The control laws from the PCA system that had been flight tested $^{2}$ were modified to approximate the lateral control mode (fig. 3). To accomplish this, the longitudinal control laws were disabled, and the left engine lateral control law commands were zeroed, leaving only the right engine thrust being modulated to control track angle, with feedbacks of roll rate, yaw rate, bank angle, and track. The lateral control with gains unmodified from the standard MD-11 PCA system provided stable track control.

Figure 11 shows the MD-11 with $\mathrm{CGY}=31$ in., an altitude of $15,000 \mathrm{ft}$, the left engine at idle, the center engine near idle, and the right engine being controlled by the unmodified PCA lateral control laws to hold track. As seen, track control is very sluggish and has a $5^{\circ}$ steady-state bias but is stable. The $12^{\circ}$ commanded track change command just before $1600 \mathrm{sec}$ took more than $50 \mathrm{sec}$ to complete. The dutch-roll oscillation seen in the roll rate parameter slowly damped. The longitudinal control using fuel transfer had not been implemented, so pitch axis was uncontrolled; the phugoid produced FPA oscillations of almost $2^{\circ}$; damping was very light.

The time history is continued in figure 12. Larger track inputs were made, and the results show that the bank angle appears to be rate limited. A small open-loop thrust increase on the center engine (to establish a climb) fortuitously damped the phugoid, but the phugoid was excited again at $t=1875 \mathrm{sec}$ when the PCA logic reduced thrust to reduce bank angle. Figure 12 also shows a reduction in bank angle feedback gain at $t=1960 \mathrm{sec}$ from 1.0 to 0.5 that was made in an attempt to decrease the steady-state track error. As may be seen, the track error was reduced from $5^{\circ}$ to $3^{\circ}$. However, the change increased the amplitude of a dutch-roll limit cycle; although track was still controlled adequately. It is encouraging that the degree of control shown in this first look was obtained without modifying the PCA lateral control laws; further research could undoubtedly improve the closed-loop track performance.

Later, simulated approaches to a runway were made. Using the track command knob, runway alignment could be achieved and accurately maintained, although a bias of several degrees was required to track the extended runway centerline. No closed-loop FPA control capability was included in this first look, but FPA could likely be controlled sufficiently for a survivable landing using either the center engine or by controlling CGY.

\section{Results of B-747 Simulation}

On the B-747 airplane, the combination of full fuel $(114,000 \mathrm{lb})$ in one wing and empty tanks in the other wing provides a CGY offset of approximately 70 in. Currently, in the B-747-400, this fuel loading cannot be accomplished actively in flight using fuel transfer pumps but could be accomplished in flight through fuel burnout by shutting off appropriate fuel pumps. Changes would have to be incorporated into the fuel management system to provide a capability to transfer fuel from one wing to the other.

In the simulator, however, the operator could put full fuel in the right wing tanks and empty the left wing tanks. With all dampers turned off, and flight controls not used, with all fuel in the right wing, flying at $10,000 \mathrm{ft}$, essentially level flight is possible with the inboard engine at high power and the outboard engine at low power and modulated to maintain the desired bank angle. Manual throttles-only control (using the outboard engine primarily for roll control and the inboard primarily for pitch control); the scheme shown in figure 4 is adequate to maintain flight, but even gross control is initially very difficult. After some practice, it is possible to achieve a degree of heading control, but flightpath control is still extremely difficult.

At an airspeed of about $220 \mathrm{kn}$, with gear and flaps up and both left engines shut down, the B-747 simulation could be stabilized. The thrust required for level flight was relatively low and was achieved with the right inboard engine at an EPR of 1.3 and the right outboard engine at an EPR of 1.0. Throttle step response tests were performed in the simulator to determine the roll rates that could be achieved. Figure 13 shows an openloop throttle step input on the outboard engine (engine 4). Thrust was initially increased on engine 4, which resulted in a $30^{\circ}$ bank angle in $12 \mathrm{sec}$, with a maximum roll rate of $6 \% \mathrm{sec}$. The throttle was then reduced to idle, which resulted in a slower roll back to wings-level flight with a maximum roll rate of $3 \% \mathrm{sec}$. 

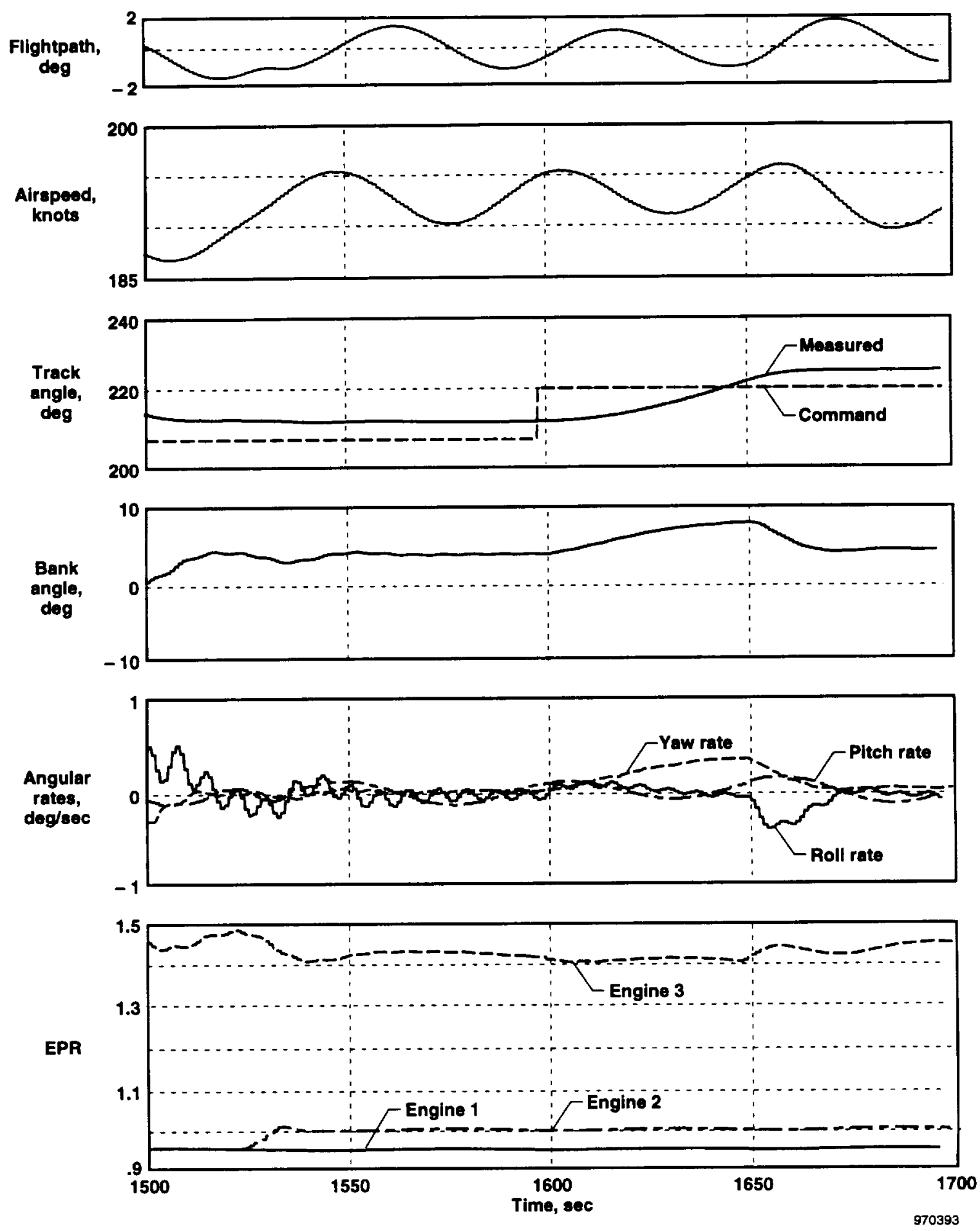

Figure 11. Time history of MD-11 FDS single-wing engine lateral closed-loop operation with CGY = 31 in.; left engine at idle; altitude $=15,000 \mathrm{ft}$; weight $=380,000 \mathrm{lb}$; gear and flaps up; MD-11 lateral PCA control laws. 


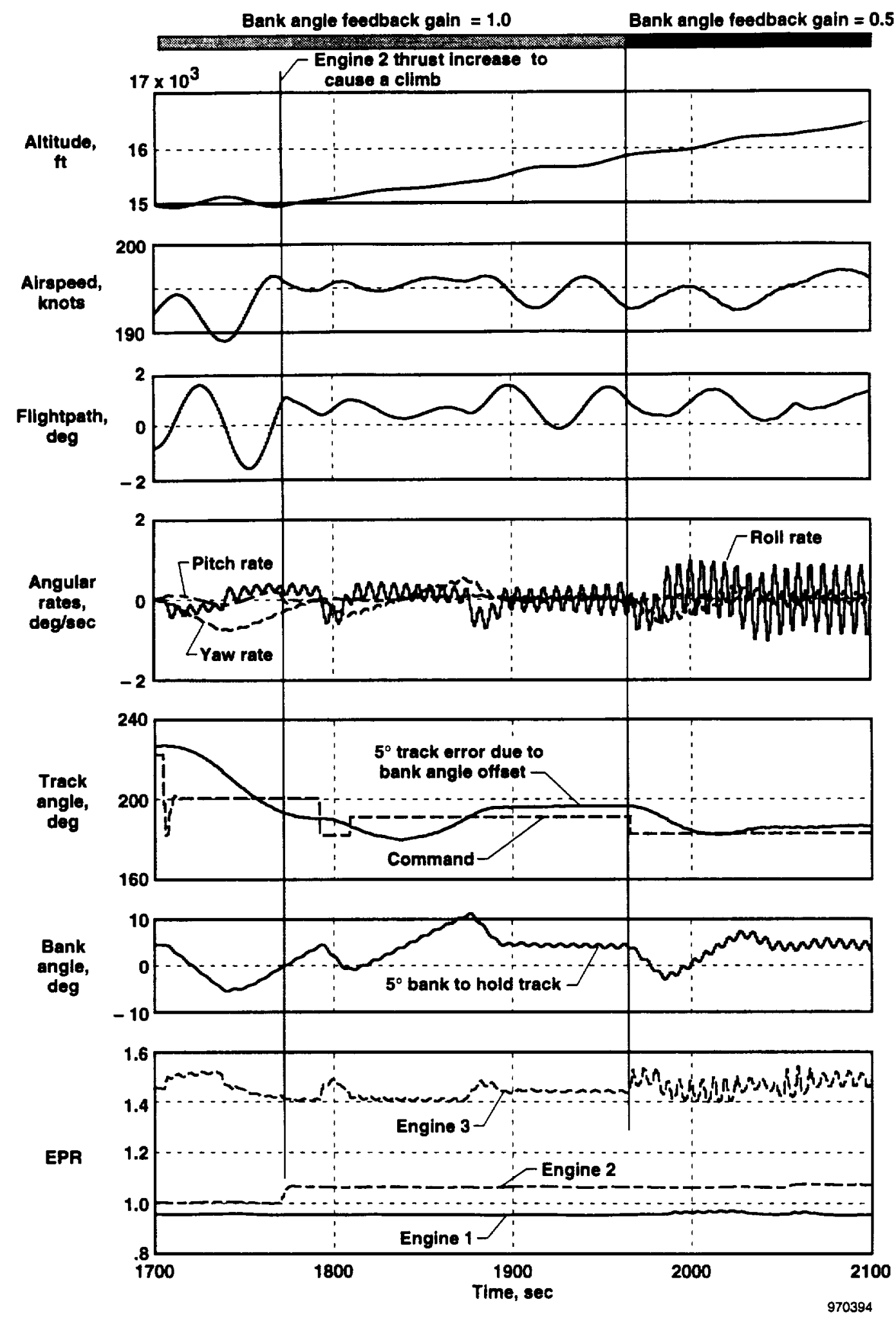

Figure 12. Time history of MD-11 FDS PCA system lateral control; CGY = 31 in.; gear and flaps up; dampers off; no fight control; left engine idle. 


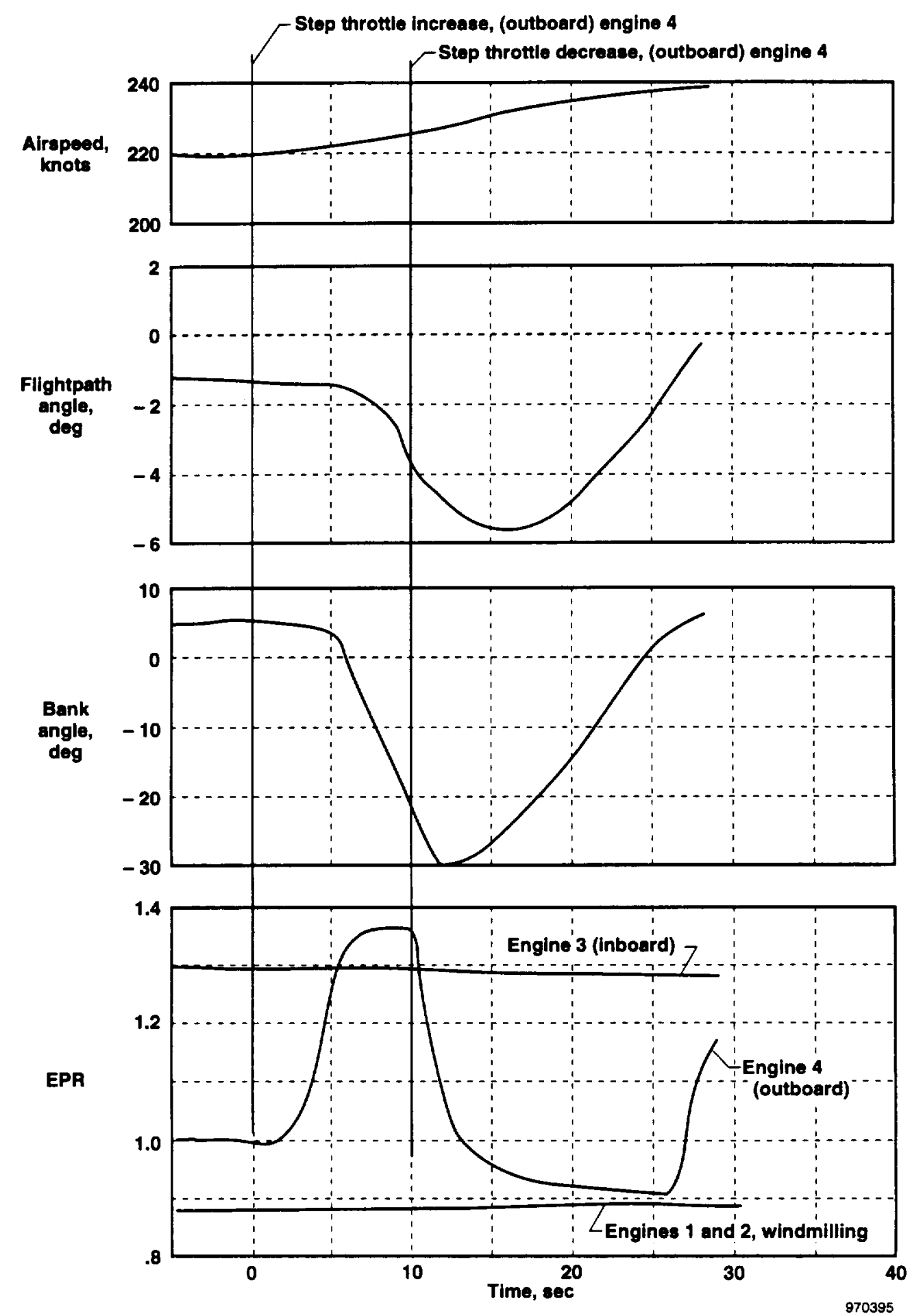

Figure 13. Time history of B-747 simulation open-loop throttle step on engine 4 ; CGY $=70$ in.; gear and flaps up; dampers off; engines 1 and 2 off; no flight control inputs. 
Similar step throttle response tests were performed on the right inboard engine (engine 3). Roll rate was $1.3 \% \mathrm{sec}$ for a throttle decrease to idle, and $0.7 \% \mathrm{sec}$ for a throttle increase.

Figure 14 summarizes the roll rates at 255,223 , and $220 \mathrm{kn}$ as a function of change in EPR for inboard and outboard engines. The data show a nearly linear relationship, as would be expected, with some curve because of the nonlinear relationship of thrust to EPR. The moment arm on the inboard engine is about equal to $33 \mathrm{ft}$ while the moment arm on the outboard engine is about equal to $64 \mathrm{ft}$; so the outboard engine develops approximately twice as much rolling moment. These data allow maximum roll rates to be computed for given inboard and outboard throttle settings. Roll rates of approximately $3 \% \mathrm{sec}$ are generally needed for safe runway landings and should generally be available for the B-747. An exception is when the outboard engine is running near idle thrust, in which case turns in the direction of the operating engines will be very sluggish, with roll rates possibly only $1^{\circ}$ or $2^{\circ} / \mathrm{sec}$.

After making these throttle steps with pilot throttle inputs, directional control had been practiced to the point where an approach to the runway was attempted. Figure 15 shows a time history of $5 \mathrm{~min}$ of manual throttles-only control. The B-747 was initially trimmed with the CGY $=70$ in., engine 3 at an EPR of 1.3, engine 4 at $1.02 \mathrm{EPR}$, and engines 1 and 2 shut down and windmilling. At an altitude of $5500 \mathrm{ft}$, the sideslip required for wings-level flight was approximately $4^{\circ}$. The response to an inboard engine throttle step was tested between $t=10$ and $35 \mathrm{sec}$, with results that were previously discussed.

With the runway about $25 \mathrm{mi}$ ahead and displaced approximately $6 \mathrm{mi}$ to the right, acquisition of the extended runway centerline was attempted. A turn to the right was initiated by retarding the inboard throttle with the idea of also starting a descent. The bank angle became excessive, which also allowed the nose to drop; therefore, the outboard engine thrust was increased to reduce the bank angle. The phugoid was excited by the excessive nose-down attitude. At $t=95 \mathrm{sec}$, the bank needed to be reversed for a left turn, and engine 4 was increased to an EPR of 1.2; at the same time the EPR of engine 3 was reduced in an attempt to lower the nose. At $t=120 \mathrm{sec}$, the landing gear was lowered, causing a significant increase in drag and thrust required to maintain the glideslope. It also reduced the average airspeed from 225 to $215 \mathrm{kn}$. The throttle on engine 3 was gradually advanced and engine 4 was retarded to try to hold a $3^{\circ}$ glideslope; it only held to within $\pm 2^{\circ}$. The extended runway centerline was tracked within approximately $\pm 1500 \mathrm{ft}$ during the last $150 \mathrm{sec}$ of data shown, with an average bank angle of approximately $4^{\circ}$ required to offset the sideslip. With the gear extended, it

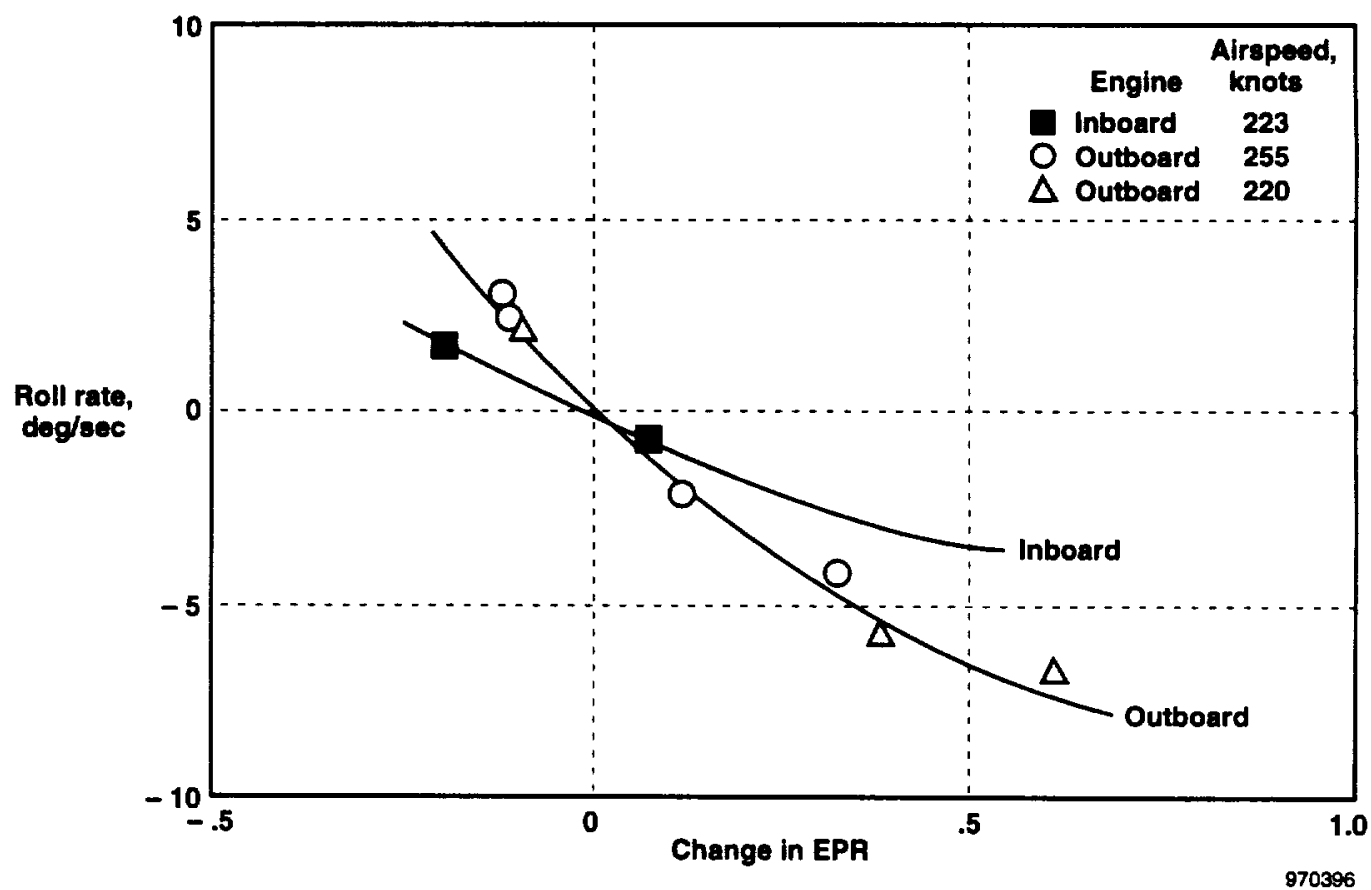

Figure 14. Roll rate as a function of change in EPR on the B-747; altitude $\approx 10,000 \mathrm{ft}$; gear and flaps up. 

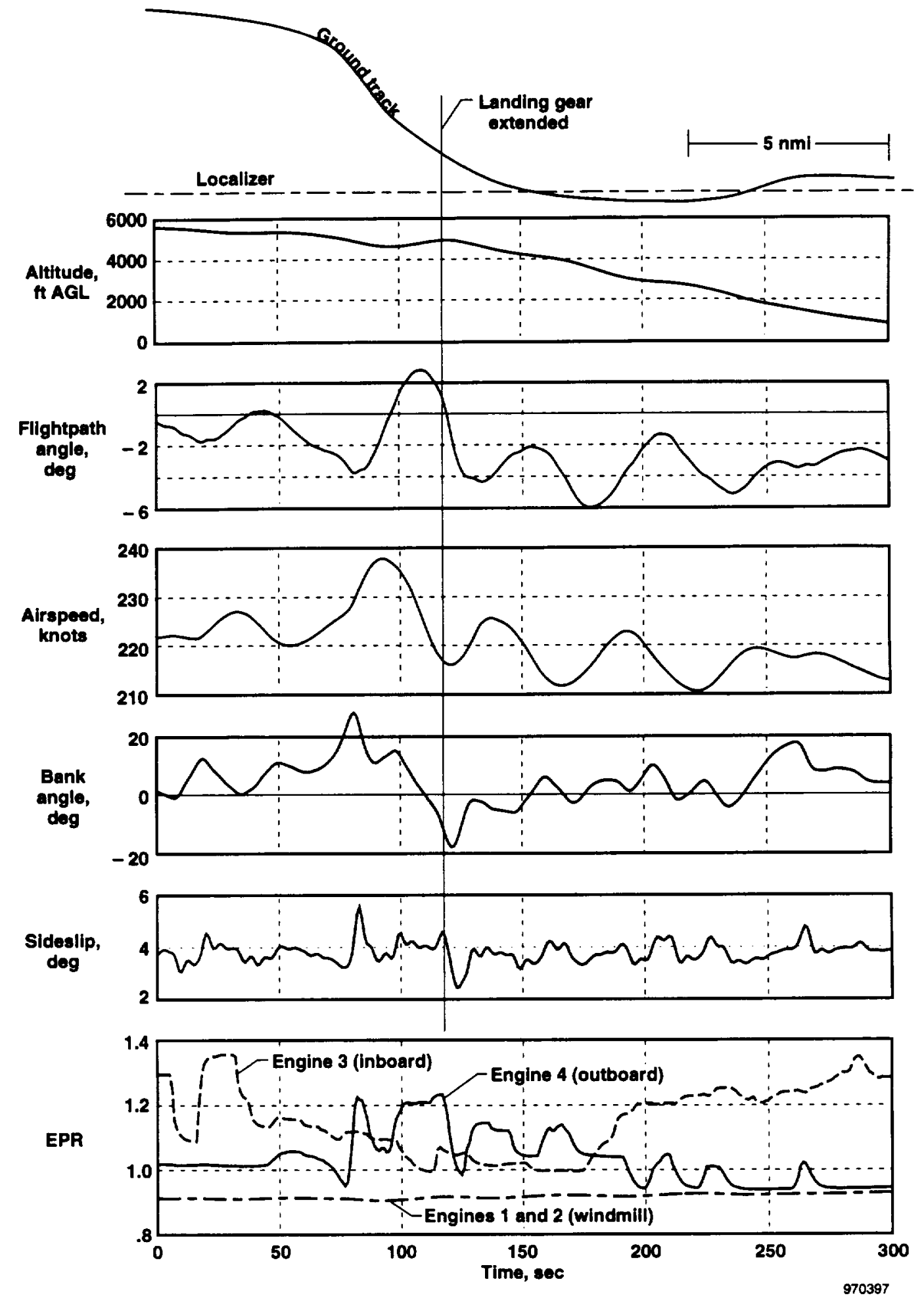

Figure 15. Time history of manual throttles-only approach with B-747-400 simulation; no flight controls; both left engines shut down; $\mathrm{CGY}=70 \mathrm{in}$; f flaps up; $\mathrm{GW}=614,000 \mathrm{lb}$. 
was found that level flight was no longer possible. The lower trim speed increased the drag, and combined with the drag of the gear, increased the drag above the thrust available for wings-level flight. If the approach had been continued, the landing would have been short of the runway. In other tests not shown, at a speed of $180 \mathrm{kn}, 5^{\circ}$ of sideslip was required for wings-level flight.

This time history (fig. 15) does show that gross control can be maintained with thrust only on one wing and with the CGY offset. The figure also shows that bank angle and phugoid control are very difficult, and that flightpath capability may be strongly affected by the airplane configuration, that is, landing gear extension. The PCA system developed and evaluated at NASA Ames on the B-747 has not been implemented for the CGY offset case, but it would be expected to provide improved lateral control. The quality of pitch control is uncertain at this time but should be adequate for a survivable landing. However, careful planning would be required to avoid landing short of the intended landing site. These tests were all performed with $C G Y=70$ in., which is the maximum obtainable on the B-747.

\section{Twin-Engine Airplane Control}

For a twin-engine airplane, lateral control should be similar to the MD-11, but pitch control will be very difficult. The longitudinal phugoid could possibly be damped with gentle turns made at the appropriate points in the phugoid cycle. Flightpath control would be a function of the CGY offset, which is at best a very slow controller; but if the phugoid can be controlled, a survivable landing could be possible.

\section{Concluding Remarks}

A first look at using the thrust of engines on one wing with a lateral offset of the center of gravity for emergency flight control was made using high-fidelity simulations of the MD-11 and B-747 airplanes. For the transport airplanes studied, fuel transfer could cause a lateral center-of-gravity (CGY) offset ranging from 48 to 70 in. (2.4 to 3.5 percent of wingspan).

Preliminary studies using simulations of the MD-11 and B-747 airplanes have shown that, with CGY offset, wings-level flight can be maintained with manual manipulation of the throttles. Increasing thrust rolls the airplane away from the operating engine, while decreasing thrust rolls it toward the operating engine. Roll rates of about $3^{\circ}$ to $5^{\circ} / \mathrm{sec}$ are typical. A bank angle of about $5^{\circ}$ is required to hold a steady heading.
As speed increases, the sideslip (and rolling moment) for maximum thrust on the remaining wing engine decreases, making the required CGY offset less. Sideslip required for wings-level flight varies from about $1^{\circ}$ at $300 \mathrm{kn}$ to almost $5^{\circ}$ at $180 \mathrm{kn}$.

There may be a level-flight capability with a reasonable center of gravity offset; that is, the thrust required to hold wings-level is, at some speed, equal to that required for level flight. In general, increasing the CGY offset increases the average flightpath angle.

The MD-11 propulsion-controlled aircraft (PCA) system was found to provide positive closed-loop track control, even though the system used nonoptimized gains that produced sluggish response. A runway extended centerline could be acquired and accurately tracked using the Track command knob.

On the B-747, the inboard engine could be primarily used for pitch control, while the outboard engine could be used primarily for bank angle control. Using this scheme, it was possible, after much practice, to acquire and approximately maintain an extended runway centerline and set up a glideslope; however, a survivable runway landing would have been very unlikely. It is anticipated that the B-747 PCA system closed-loop control would provide adequate flightpath control for a survivable landing.

\section{References}

${ }^{1}$ Burcham, Frank W., Jr., Trindel A. Maine, C. Gordon Fullerton, and Lannie Dean Webb, Development and Flight Evaluation of an Emergency Digital Flight Control System Using Only Engine Thrust on an F-15 Airplane, NASA TP-3627, Sept. 1996.

${ }^{2}$ Burcham, Frank W., Jr., Trindel A. Maine, John J. Burken, and Drew Pappas, Development and Flight Test of an Augmented Thrust-Only Flight Control System on an MD-11 Transport Airplane, NASA TM-4745, July 1996.

${ }^{3}$ Gilyard, Glenn B., Joseph L. Conley, Jeanette Le, and Frank W. Burcham, Jr., "A Simulation Evaluation of a Four-Engine Jet Transport Using Engine Thrust Modulation for Flightpath Control," AIAA-91-2223, June 1991.

${ }^{4}$ Bull, John, Robert Mah, Gloria Davis, Joe Conley, Gordon Hardy, Jim Gibson, Matthew Blake, Don Bryant, and Diane Williams, Piloted Simulation Tests 
of Propulsion Control as Backup to Loss of Primary Flight Controls for a Mid-Size Jet Transport, NASA TM-110374, Dec. 1995.

${ }^{5}$ Bull, John, Robert Mah, Gordon Hardy, Barry Sullivan, Jerry Jones, Diane Williams, Paul Soukup, Piloted Simulation Tests of Propulsion Control as
Backup to Loss of Primany Flight Controls for a B747400 Jet Transport, NASA TM-112191, April 1997.

${ }^{6}$ Gerren, Donna S., Design, Analysis and Control of a Large Transport Utilizing Selective Engine Thrust as a Backup System for the Primary Flight Control, NASA CR-186035, Oct. 1995. 


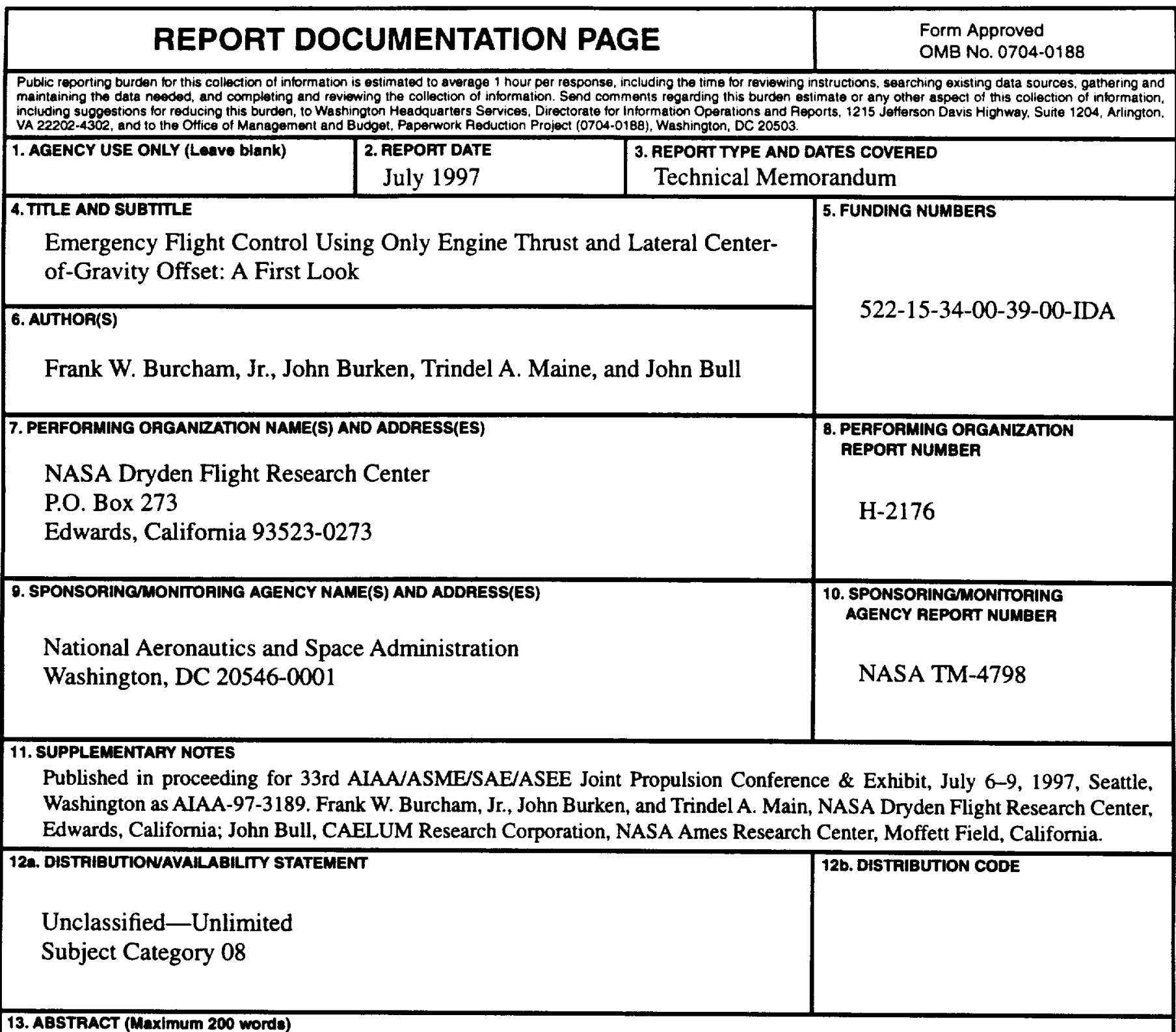

13. ABSTRACT (Maximum 200 words)

Normally, the damage that results in a total loss of the primary flight controls of a jet transport airplane, including all engines on one side, would be catastrophic. In response, NASA Dryden has conceived an emergency flight control system that uses only the thrust of a wing-mounted engine along with a lateral centerof-gravity (CGY) offset from fuel transfer. Initial analysis and simulation studies indicate that such a system works, and recent high-fidelity simulation tests on the MD-11 and B-747 suggest that the system provides enough control for a survivable landing. This paper discusses principles of flight control using only a wing engine thrust and CGY offset, along with the amount of CGY offset capability of some transport airplanes. The paper also presents simulation results of the throttle-only control capability and closed-loop control of ground track using computer-controlled thrust.

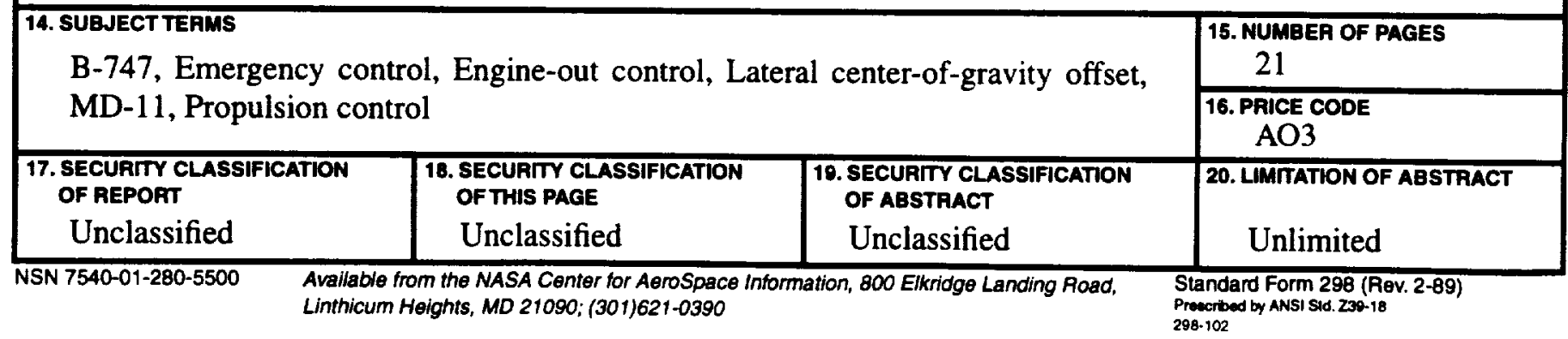

